\title{
Analisis struktur morfologi membran kitosan/peo dan kitosan/PEG4000
}

\author{
Kartika Sari1* ${ }^{1}$, Sunardi ${ }^{1}$, Agung Bambang Setio Utomo ${ }^{2}$, Edi Suharyadi ${ }^{2}$, Evvy Kartini ${ }^{3}$, Evi Yulianti ${ }^{3}$ \\ ${ }^{1}$ Jurusan Fisika, FMIPA, Universitas Jenderal Soedirman Purwokerto 53123 \\ ${ }^{2}$ Departemen Fisika, FMIPA Universitas Gadjah Mada Yogyakarta 55281 \\ ${ }^{3}$ PSTBM Batan Tenaga Atom Nasioal, Serpong 15314 \\ *email: kartika.sari@unsoed.ac.id
}

\begin{abstract}
Abstrak - Pembuatan dan pengujian membran kitosan/PEO dan kitosan/PEG4000 dilakukan bertujuan untuk membandingkan struktur morfologi dan gugus fungsi yang dihasilkan dari membran kitosan/PEO dan kitosan/PEG4000. Pembuatan membran Kitosan/PEO dan kitosan/PEG4000 dilakukan dengan metode solution casting. Karakterisasi dilakukan menggunakan FTIR (Fourier Transform Infra Red) dan SEM (Scanning Electron Microscopy). Hasil FTIR membran kitosan, kitosan/PEO dan kitosan/PEG4000 menunjukkan adanya interaksi gugus fungsi $-\mathrm{OH}$ dan $\mathrm{C}-\mathrm{H}$ di dalam membran kitosan/PEO dan kitosan/PEG4000. Bilangan gelombang $1500-945 \mathrm{~cm}^{-1}$ terbentuk ikatan bending antara gugus fungsi $\mathrm{C}-\mathrm{C}$ dan $-\mathrm{NH}_{3}$. Hasil SEM menunjukkan terbentuk aglomerasi dengan bertambahnya PEO dan PEG4000 pada larutan. Aglomerasi terjadi homogen di permukaan membran menunjukkan adanya pengaruh penambahan PEO dan PEG4000 pada pembentukan membran sehingga menghasilkan ikatan antar atom yang semakin renggang/tidak stabil. Hasil membran kitosan/PEO dan kitosan/PEG4000 dapat digunakan sebagai polimer elektrolit padat.
\end{abstract}

Kata Kunci: : Gugus fungsi, aglomerasi, kitosan, PEO, PEG4000.

\section{PENDAHULUAN}

Penggunaan kitosan dikembangkan karena sifat kitosan yang merupakan suatu biopolimer organik memiliki sifat non-toksis, biodegradable dan hidrofilik. Kitosan terdiri dari gugus fungsi amina dan hidroksil [1-3]. Sintesis kitosan diperoleh dari cangkang hewan seperti udang, kepiting dan lobster [4]. Kitosan semakin menarik dikembangkan karena ukuran partikelnya dapat dibuat nano dan luas permukaannya kecil sehingga mudah untuk dimodifikasi dengan material kimia lainnya [59].

Material kimia yang banyak digunakan untuk modifikasi kitosan adalah PEO (Polietilen Oksida) dan PEG (Polietilen Glikol) [10]. Dalam penelitian ini digunakan PEG4000. PEO dan PEG4000 berbentuk serbuk, memiliki sifat dapat larut dalam air dan methanol (hidrofilik). Hal yang menarik digunakan PEO dan PEG4000 adalah fungsi dari PEO dan PEG4000 untuk mengontrol ukuran dan struktur pori membran. PEO dan PEG4000 merupakan polimer dari etilen oksida yang memiliki perbedaan pada massa molekulnya [11].

Membran merupakan daerah tipis antara dua fase yang memiliki lintasan tertentu sehingga memungkinkan fase atau komponen tertentu menembus lebih cepat dibandingkan dengan fase atau komponen lainnya di bawah pengaruh gaya penggerak (driving force) [12]. Sintesis membran yang dilakukan dalam penelitian ini adalah dengan mencampurkan kitosan dengan PEO dan PEG4000 kemudian diuji menggunakan FTIR dan SEM. Dari hasil FTIR dan SEM memberikan informasi bahwa membran kitosan/PEO atau kitosan/PEG4000 dapat digunakan sebagai polimer elektrolit padat.

\section{METODE PENELITIAN}

\section{a. Bahan dan alat yang digunakan}

Bahan-bahan yang digunakan dalam penelitian ini adalah kitosan, asam asetat (Merck), PEO dan PEG4000 (Sigma-Aldrich). Sedangkan alat yang digunakan adalah neraca Ohauss Galaxy TM 160, hot plate stirrer Thermo scientific model Cimarec 2, mikrometer skrup, desikator vacuum $200 \mathrm{~mm}$ Vitlab, cawan petri dan gelas ukur.

\section{b. Prosedur penelitian}

Pembuatan larutan kitosan dengan menimbang kitosan sebanyak 1 gram kemudian kitosan dituangkan ke dalam gelas ukur yang berisi larutan asam asetat sebanyak $100 \mathrm{ml}$ kemudian diaduk dengan menggunakan 
magnetik stirrer dengan variasi kecepatan dan suhu selama 15 menit. Tambahkan sedikit demi sedikit PEO atau PEG4000 ke dalam larutan kitosan 1\% sambil distirrer sampai habis selama 1 jam hingga larutan kitosan/PEO atau kitosan/PEG4000 homogen. Larutan kitosan/PEO dan kitosan/PEG 4000 dicetak ke dalam cawan petri dan dikeringkan pada suhu $60{ }^{0} \mathrm{C}$ selama 2 hari menggunakan dried box. Membran yang sudah kering dan siap dilakukan pengujian.

\section{c. Karakterisasi membran kitosan/PEO dan kitosan/PEG4000}

Spektra FTIR membran kitosan/PEO dan kitosan/PEG4000 diperoleh dengan menggunakan Shimadzu 8201 PC FTIR spektrofotometer dan direkam dengan resolusi 1 $\mathrm{cm}^{-1}$ dengan rentang bilangan gelombang dari 400 hingga $4000 \mathrm{~cm}^{-1}$ untuk menentukan gugus fungsi. Struktur mikro dan distribusi grain size menggunakan Scanning Electron Microscopy (SEM) tipe JEOL, JSM-6510LA dengan pembesaran 1000x pada suhu kamar. Sampel dilapisi dengan emas menggunakan arus listrik, $\mathrm{I}=60 \mathrm{~mA}$ selama 100 detik. Prosedur ini dilakukan untuk mendapatkan kualitas gambar yang lebih baik.

\section{HASIL DAN PEMBAHASAN}

\section{a. FTIR membran kitosan, kitosan/PEO dan kitosan/PEG4000}

Hasil FTIR membran kitosan dapat dilihat pada Gambar 1. Membran kitosan daerah serapan terjadi pada bilangan gelombang $2000-$ $1000 \mathrm{~cm}^{-1}$. Daerah serapan juga terjadi pada bilangan gelombang $1701 \mathrm{~cm}^{-1}$ yang menunjukkan gugus fungsi $\mathrm{C}=\mathrm{O}$ asimetri dan pada $1430 \mathrm{~cm}^{-1}$ terjadi gugus fungsi $\mathrm{C}=\mathrm{O}$ simetri dari kitosan. Daerah bilangan gelombang $2301 \mathrm{~cm}^{-1}$ gugus fungsi $\mathrm{C}-\mathrm{OH}$ bending. Daerah bilangan gelombang 1651 $600 \mathrm{~cm}^{-1}$ menunjukkan gugus fungsi $\mathrm{C}=\mathrm{O}$, sedangkan daerah bilangan gelombang 3000 $2500 \mathrm{~cm}^{-1}$ terbentuk gugus $\mathrm{C}-\mathrm{H}$ bending. Puncak $3500 \mathrm{~cm}^{-1}$ membentuk gugus fungsi $\mathrm{O}$ $\mathrm{H}$ bending.

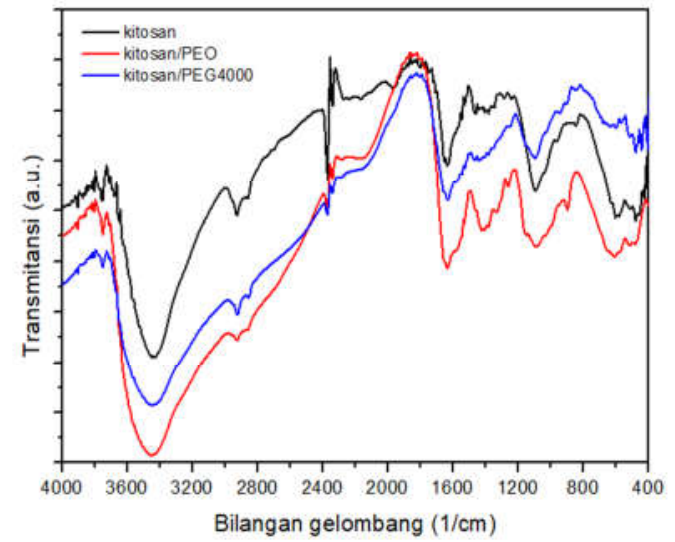

Gambar 1. FTIR membran kitosan, kitosan/PEO dan kitosan/PEG4000

Membran kitosan/PEO menunjukkan gugus fungsi $\mathrm{O}-\mathrm{H}$ terjadi pada bilangan gelombang $3449 \mathrm{~cm}^{-1}$. Gugus fungsi C-H (streching) terjadi pada bilangan gelombang $2924 \mathrm{~cm}^{-1}$ dan pada bilangan gelombang $2237 \mathrm{~cm}^{-1}$ terjadi $\mathrm{C}-\mathrm{H}$ bending. Untuk daerah gelombang $1636 \mathrm{~cm}^{-1}$ terjadi gugus fungsi $\mathrm{C}=\mathrm{O}$. Sedangkan daerah gelombang $1096 \mathrm{~cm}^{-1}$ terjadi gugus fungsi C-O dan $\mathrm{NH}_{3}$. Daerah gelombang $964-841 \mathrm{~cm}^{-1}$ menunjukkan gugus fungsi C-O-C dan $602-$ $478 \mathrm{~cm}^{-1}$ merupakan gugus fungsi C-C.

Hasil FTIR membran kitosan/PEG4000 menunjukkan bahwa gugus fungsi $-\mathrm{OH}$ terjadi pada daerah bilangan gelombang $3448 \mathrm{~cm}^{-1}$. Daerah bilangan gelombang $2924 \mathrm{~cm}^{-1}$ menunjukkan terbentuknya gugus fungsi C-H. Sedangkan pada daerah bilangan 2855 - 2338 $\mathrm{cm}^{-1}$ terbentuk gugus fungsi $\mathrm{C}-\mathrm{H}$ stretching. Gugus fungsi $\mathrm{C}-\mathrm{O}$ dan $\mathrm{NH}_{3}$ terbentuk pada daerah bilangan $1635 \mathrm{~cm}^{-1}$. Daerah bilangan gelombang $1096 \mathrm{~cm}^{-1}$ dan $478 \mathrm{~cm}^{-1}$ terbentuk ikatan C-O dan ikatan C-C.

\section{b. SEM}

Hasil SEM membran kitosan, kitosan/PEO dan kitosan/PEG4000 dapat dilihat pada Gambar 2, Gambar 3 dan Gambar 4. 


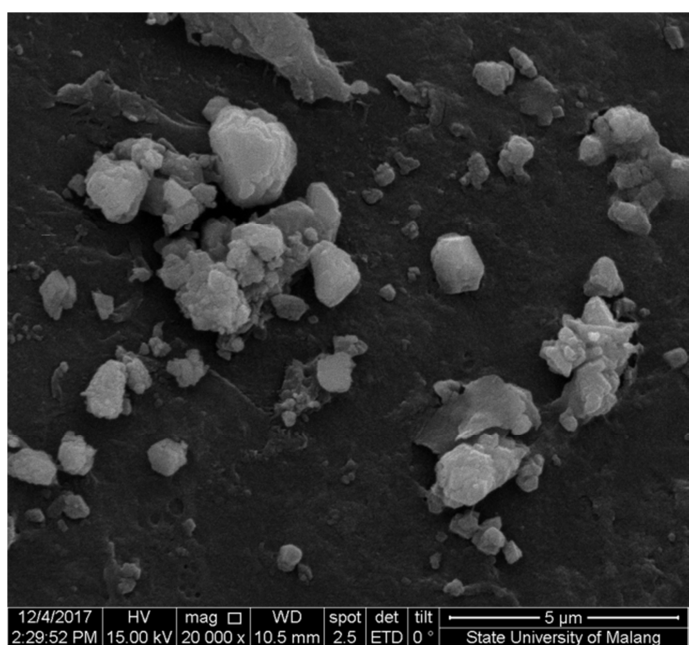

Gambar 2. Membran kitosan

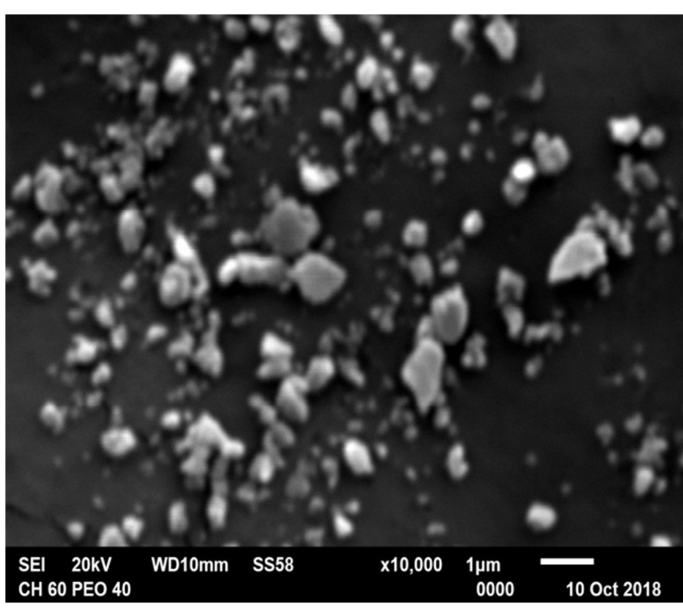

Gambar 3. Membran kitosan/PEO

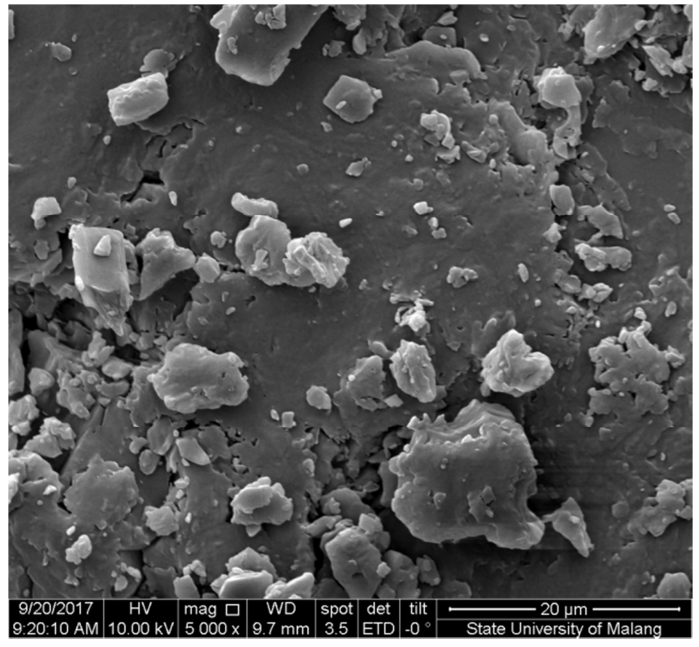

Gambar 4. Membran kitosan/PEG4000

Gambar 2, 3, dan 4 menunjukkan struktur morfologi permukaan terdiri dari distribusi butiran menyebar homogen dan aglomerasi antara molekul-molekul penyusun kitosan, PEO dan PEG4000 serta cenderung berpori. Ukuran butiran penyusun membran kitosan adalah 15,1 $\mathrm{nm}$, kitosan/PEO adalah 11,30 nm dan kitosan/PEG4000 adalah 10,35 nm.

Perubahan struktur permukaan membran disebabkan masuknya ion $-\mathrm{NH}_{3}$ ke dalam poripori yang bisa memudahkan kontak antar partikel dalam membran. Kontak antar partikel tersebut akan menyebabkan membran lebih fleksibel, stabil ukuran, dimensi dan memiliki kation atau anion bebas bergerak yang akan berfungsi sebagai pembawa muatan serta tidak bersifat higrokopis. Membran yang dihasilkan lebih tipis, tidak kaku dan tidak akan berubah bentuk serta tidak mudah menyerap air.

Membran yang memiliki sifat tersebut dapat digunakan sebagai elektrolit padat. Jadi dapat disimpulkan bahwa kitosan/PEO dan kitosan/PEG4000 dapat digunakan sebagai polimer elektrolit padat untuk aplikasi baterai sekunder.

\section{KESIMPULAN DAN SARAN}

Dari penelitian yang telah dilakukan dapat diambil kesimpulan bahwa :

1. Terjadi pembentukan gugus fungsi baru $-\mathrm{OH}$ pada kitosan/PEO dan kitosan/PEG4000 pada panjang gelombang $3500 \mathrm{~cm}^{-1}$ dan terjadi interaksi ikatan bending antara $-\mathrm{OH}$ dan $\mathrm{NH}_{3}$ pada panjang gelombang $1500-$ $945 \mathrm{~cm}^{-1}$.

2. Kitosan/PEO dan kitosan PEG4000 menghasilkan membran lebih fleksibel dan tidak bersifat higroskopis.

3. Kitosan/PEO dan kitosan/PEG4000 dapat digunakan sebagai bahan alternatif sebagai membran polimer elektrolit padat baterai sekunder.

\section{UCAPAN TERIMA KASIH}

Terima kasih kepada Kementrian Ristek/BRIN melalui Universitas Jenderal Soedirman melalui pendanaan BLU Skim Riset Peningkatan Kompetensi Tahun 2020.

\section{DAFTAR PUSTAKA}

[1] O. G. Abdullah, R. R. Hanna, Y. A. K. Salman, "Structural, optical, and electrical characterization of chitosan: methylcellulose polymer blends based film," J. Mater. Sci. Mater. Electron. 28(14) (2017) 10283-10294. 
[2] S.Kartika, BSU. Agung, A. Abraha, Roto, K. Evvy, Y. Evi, S. Edi., IJENeaM 13(1) (2020) 1-8. .

[3] A. Badawi, E. M. Ahmed, N. Y. Mostafa, F. Abdel-Wahab, S. E. Alomairy, "Enhancement of the optical and mechanical properties of chitosan using $\mathrm{Fe}_{2} \mathrm{O}_{3}$ nanoparticles," J. Mater. Sci. Mater. Electron. 28(15) (2017) 1087710884.

[4] S. Kartika, S. Edi, Roto, A. Kamsul, Material Science Forum 948 (2018) 192$197 .$.

[5] W. Zhang, J. Zhang, W. Xia, "Effect of ball-milling treatment on physicochemical and structural properties of chitosan," Int. J. Food Prop. 17(1) (2014) 26-37.

[6] Rochima, E., Azhary, S.Y., Prata, R.I., Panatarani, C., Joni, I.M, "Preparation and characterization of nano chitosan from crab shell waste by beads milling method", International conference on Food Science and Engineering (2016) 193.

[7] Liu, T.Y., Ma, Y., Yu, S.F., Shi, J., Xue, S., "The effect of ball milling treatment on structure and porosity of maize starch granule", Innovative Food Science and Emerging Technologies (2011) 586-593.
[8] Zhan, W., Zhang, J., Xia, W. "Effect of ball milling treatment on physicochemical and structural properties of chitosan", International Journal of Food Properties (2014) 26-37.

[9] Ker, W.L., Ward, SDW., McWatters, KH., Resurreccion, AVA., Effect of milling and particle size on functionality and physicochemical properties of cowpea flour, American Association of Cereal Chemists Inc. Publication no. C2000-0212-02R. (2000).

[10] M. Barchuk et al., "Structure and surface properties of chitosan/PEO/gelatin nanofibrous membrane," J. Polym. Res. 23 (2) (2016) 1-7.

[11] A. Datta, Characterization of Polyethylene Glycol Hydrogels for Biomedical Applications, Thesis, University of Pune, India, (2007).

[12] M. Mulder, Basic Principles of Membran Technology, Khewer Academic Publisher. (1991).

[13] Shukur. MF., Ithnin. R., Kadir. MFZ, Proton Conducting polymer electrolyte based on plasticitized chitosan/PEO blend and application in electrochemical devices. Optical Materials 5 (2013) 1834-1841. 